Article

\title{
Repurposing Benzbromarone for Familial Amyloid Polyneuropathy: A New Transthyretin Tetramer Stabilizer
}

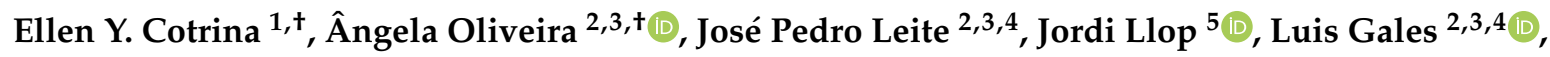 \\ Jordi Quintana ${ }^{6}\left(\mathbb{D}\right.$, Isabel Cardoso $2,3,4, * \mathbb{D}$ and Gemma Arsequell ${ }^{1, *(D)}$ \\ 1 Institut de Química Avançada de Catalunya (I.Q.A.C.-C.S.I.C.), 08034 Barcelona, Spain; \\ ellen.cotrina@iqac.csic.es \\ 2 IBMC - Instituto de Biologia Molecular e Celular, 4200-135 Porto, Portugal; \\ angela.d.a.oliveira@gmail.com (Â.O.); jose.leite@ibmc.up.pt (J.P.L.); lgales@ibmc.up.pt (L.G.) \\ 3 i3S-Instituto de Investigação e Inovação em Saúde, Universidade do Porto, 4200-135 Porto, Portugal \\ 4 Instituto de Ciências Biomédicas Abel Salazar (ICBAS), 4050-013 Porto, Portugal \\ 5 CIC biomaGUNE, Basque Research and Technology Alliance (BRTA), 20014 San Sebastian, Spain; \\ jllop@cicbiomagune.es \\ 6 Research Programme on Biomedical Informatics, Universitat Pompeu Fabra (UPF-IMIM), \\ 08003 Barcelona, Spain; jordiramon.quintana@upf.edu \\ * Correspondence: icardoso@ibmc.up.pt (I.C.); gemma.arsequell@iqac.csic.es (G.A.) \\ + These authors contributed equally to this work.
}

Received: 9 September 2020; Accepted: 24 September 2020; Published: 28 September 2020

\begin{abstract}
Transthyretin (TTR) is a homotetrameric protein involved in human amyloidosis, including familial amyloid polyneuropathy (FAP). Discovering small-molecule stabilizers of the TTR tetramer is a therapeutic strategy for these diseases. Tafamidis, the only approved drug for FAP treatment, is not effective for all patients. Herein, we discovered that benzbromarone (BBM), a uricosuric drug, is an effective TTR stabilizer and inhibitor against TTR amyloid fibril formation. BBM rendered TTR more resistant to urea denaturation, similarly to iododiflunisal (IDIF), a very potent TTR stabilizer. BBM competes with thyroxine for binding in the TTR central channel, with an IC $\mathrm{C}_{50}$ similar to IDIF and tafamidis. Results obtained by isothermal titration calorimetry (ITC) demonstrated that BBM binds TTR with an affinity similar to IDIF, tolcapone and tafamidis, confirming BBM as a potent binder of TTR. The crystal structure of the BBM-TTR complex shows two molecules binding deeply in the thyroxine binding channel, forming strong intermonomer hydrogen bonds and increasing the stability of the TTR tetramer. Finally, kinetic analysis of the ability of BBM to inhibit TTR fibrillogenesis at acidic $\mathrm{pH}$ and comparison with other stabilizers revealed that benzbromarone is a potent inhibitor of TTR amyloidogenesis, adding a new interesting scaffold for drug design of TTR stabilizers.
\end{abstract}

Keywords: benzbromarone; drug; transthyretin tetramer stabilizer; transthyretin; drug repurposing; native kinetic stabilization; dibromophenol scaffold

\section{Introduction}

Transthyretin (TTR) is a protein of 127 amino acids that self-assembles as a $55 \mathrm{kDa}$ homotetramer that is secreted into the bloodstream by the liver [1,2] and into the cerebrospinal fluid (CSF) by the choroid plexus [3]. TTR transports holo-retinol-binding protein in the blood, forming a macromolecular complex [4,5]. The protein acts as a backup carrier of thyroxine (T4) in serum (crystal structure in Figure 1), where the principal transporters are thyroid-binding globulin (TBG) and albumin, while being the primary carrier of T4 in CSF. The T4-binding sites at the weaker of the two dimer-dimer interfaces of 
TTR are largely unoccupied in human blood and CSF [6]. TTR likely has additional unknown functions, especially in the brain [7]. In fact, TTR is also known as a neuroprotective protein in Alzheimer's disease (AD) [8-10].
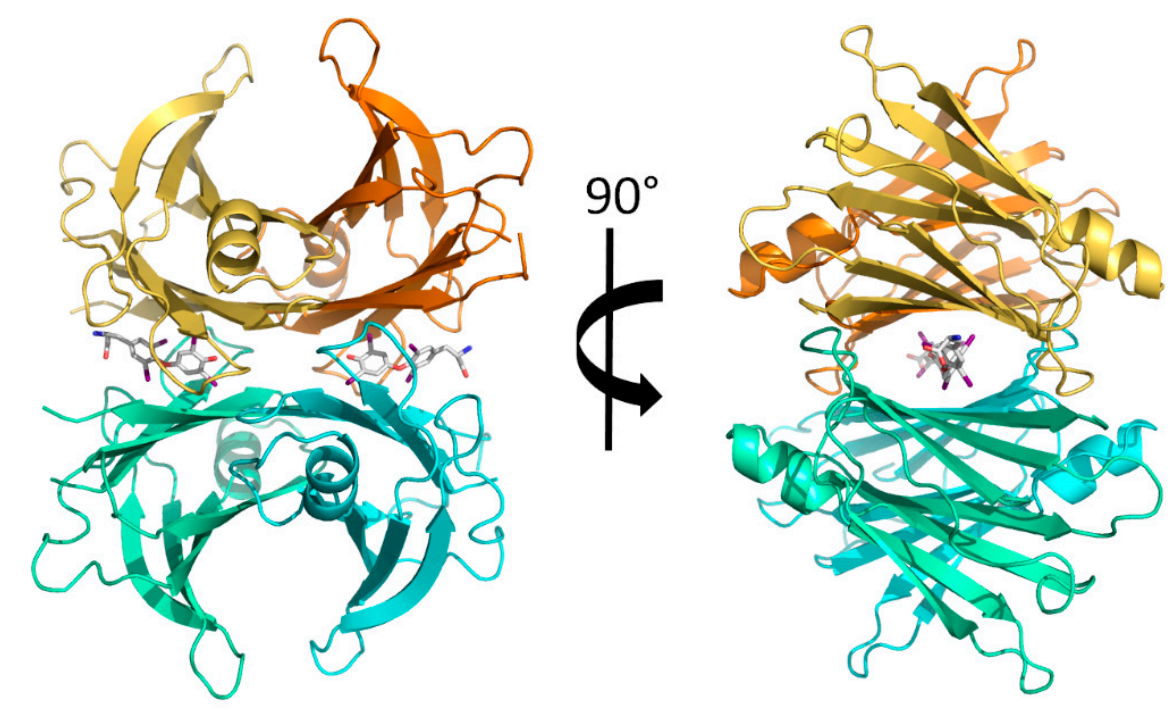

Figure 1. Crystal structure of transthyretin (TTR) bound to the natural ligand thyroxine (T4, PDB ID: 2ROX). The functional TTR homotetramer is assembled by two TTR dimers, AB in orange and A'B' in cyan.

TTR has been the subject of intensive research in the last 30 years because of its pathogenic properties. Transthyretin (TTR) amyloidoses are a group of systemic degenerative diseases involving multiple organ systems and are caused by TTR aggregation [11], such as familial amyloid polyneuropathy (FAP) [12], familial amyloid cardiomyopathy (FAC) [13], senile systemic amyloidosis [14] and leptomeningeal amyloidosis [15].

Extensive efforts have been made in the past to investigate the aggregation pathway of TTR and to discover small-molecule compounds that stabilize the natively folded, non-amyloidogenic, tetrameric structure of the protein by docking on its $\mathrm{T} 4$ binding pocket and preventing its aggregation. This pharmacological discovery was referred to as the native kinetic stabilization strategy [16]. The synthetic chemistry efforts ultimately yielded $>1000$ small-molecule TTR kinetic stabilizers that are potent aggregation inhibitors.

Currently, more than 400 crystallographic structures of TTR are deposited in the Protein Data Bank (http://www.rcsb.org) [17], most of them in complex with small-molecule ligands. This comprehensive work has allowed a full characterization of the TTR binding sites [18-20]. A relevant feature of these sites is the presence of three sets of symmetry-related depressions termed halogen-binding pockets (HBPs: HBP1 and HBP1', HBP2 and HBP2' and HBP3 and HBP3'), which accommodate the iodine atoms of the thyroid hormones in their complexes with TTR [21]. The innermost pockets are HBP3 and HBP3' and the outermost HBP1 and HBP1'.

To date, only tafamidis (registered as Vyndaqel ${ }^{\circledR}$; Scheme 1) [22], a benzoxazole derivative fashioned by structure-based drug design, and a repurposed drug, the non-steroidal anti-inflammatory drug (NSAID) diflunisal (Scheme 1) [23], have reached approval for clinical use. The drug tolcapone (Scheme 1), an orally active catechol-O-methyltransferase (COMT) inhibitor authorized in the United States and Europe as an adjunct to levodopa and carbidopa for the treatment of Parkinson's disease, has also been repurposed for FAP [24]. 
<smiles>O=C(O)c1ccc2nc(-c3cc(Cl)cc(Cl)c3)oc2c1</smiles>

TAFAMIDIS

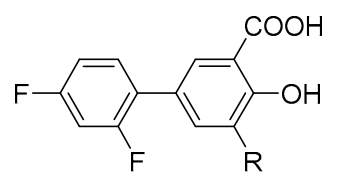

R: H DIFLUNISAL

R:I IODODIFLUNISAL<smiles>Cc1ccc(C(=O)c2cc(O)c(O)c([N+](=O)[O-])c2)cc1</smiles>

TOLCAPONE

Scheme 1. Chemical structures of TTR tetramer stabilizers: the orphan drug tafamidis, the Non-steroidal anti-inflammatory drug (NSAID) diflunisal, the repurposed drug tolcapone for Familial amyloid polyneuropathy (FAP) and our lead compound iododiflunisal (IDIF).

The drug discovery effort focused on TTR amyloid diseases continues, exemplified by the discovery of the small-molecule stabilizer AG10, now in a phase 3 trial (NCT03860935) [25].

One of our contributions to this ongoing drug discovery effort has been the preclinical development of iododiflunisal (IDIF, Scheme 1) [26-28] an iodinated derivative of the NSAID diflunisal.

Interestingly, a high percentage of the TTR T4-binding tetramer stabilizers reported in the Protein Data Bank [17] are halogenated phenol compounds (Supporting Information, Table S2). Some brominated ligands of TTR are pentabromophenol (PBP; Scheme 2) [29] and the flame retardant tetrabromobisphenol A (TBBPA; Scheme 2) [30]. TBBPA binds in the thyroxine-binding pocket, with bromines occupying two of the three halogen-binding sites. According to the authors, this molecule represents an interesting scaffold. Moreover, the effect of the halogenation on the biological activity of previously reported TTR tetramer stabilizers has also been assayed to provide mechanistic insights into their binding properties [31-33].<smiles>CCc1oc2ccccc2c1C(=O)c1cc(Br)c(O)c(Br)c1</smiles>

BENZBROMARONE (BBM)<smiles>Oc1c(Br)cc(Br)cc1Br</smiles>

Pentabromophenol (PBP)<smiles>CC(C)(c1cc(Br)c(O)c(Br)c1)c1cc(Br)c(O)c(Br)c1</smiles>

Tetrabromobisphenol A (TBBPA)

Scheme 2. Chemical structures of the small-molecule compounds sharing a dibromophenol scaffold: the drug benzbromarone (BBM) and the TTR ligands pentabromophenol (PBP, PDB ID: IE3F) and tetrabromobisphenol A (TBBPA, PDB ID: 5HJG).

The drug benzbromarone (BBM; Scheme 2) shares with TBBPA an interesting dibromophenol scaffold for drug design, being a candidate drug for repurposing purposes [34]. BBM has been used for more than 30 years to control hyperuricemia and gout $[35,36]$. Interest in this drug was found in other recent research studies. BBM was reported to be an effective inhibitor of amylin aggregation [37]. BBM was shown to inhibit retinol-dependent RBP4-TTR interaction for treatment of age-related macular degeneration [38].

In the present work, we investigated the potential of the registered drug BBM as a TTR tetramer stabilizer. To this end, we report a comparative in vitro and ex vivo study of the binding affinity of BBM to TTR; a comparative ITC analysis of the thermodynamic profile of the TTR/BBM with other stabilizers; an X-ray analysis of the molecular details of the binary interaction of BBM with TTR resulting in a strong TTR tetramer stabilization; and a comparative kinetic analysis of TTR fibrillogenesis in the presence of BBM with other stabilizers. 


\section{Results and Discussion}

\subsection{Benzbromarone (BBM) Stabilizes the TTR Tetrameric Fold}

To determine if BBM fits the native kinetic stabilization strategy, we investigated the effect of BBM in TTR stability by measuring TTR resistance to urea denaturation, as previously described [39]. The extent of denaturation of the TTR tetramer was evaluated by measuring how much folded TTR (tetramer, trimer and dimer) and monomer remained after urea treatment. We compared the effect of BBM to iododiflunisal (IDIF), known to be a potent TTR stabilizer, used here as a positive control, and also to sulfaquinoxaline, a compound that does not stabilize TTR and used here as a negative control.

As depicted in Figure 2, pre-incubation of TTR with BBM increased the resistance of TTR to urea denaturation, as compared to TTR alone. The level of TTR stabilization provided by BBM was comparable to the one by IDIF. As expected, the compound sulfaquinoxaline, used as a negative control, did not change the levels of folded/monomeric TTR, which were found to be similar to the ones in TTR incubated alone.
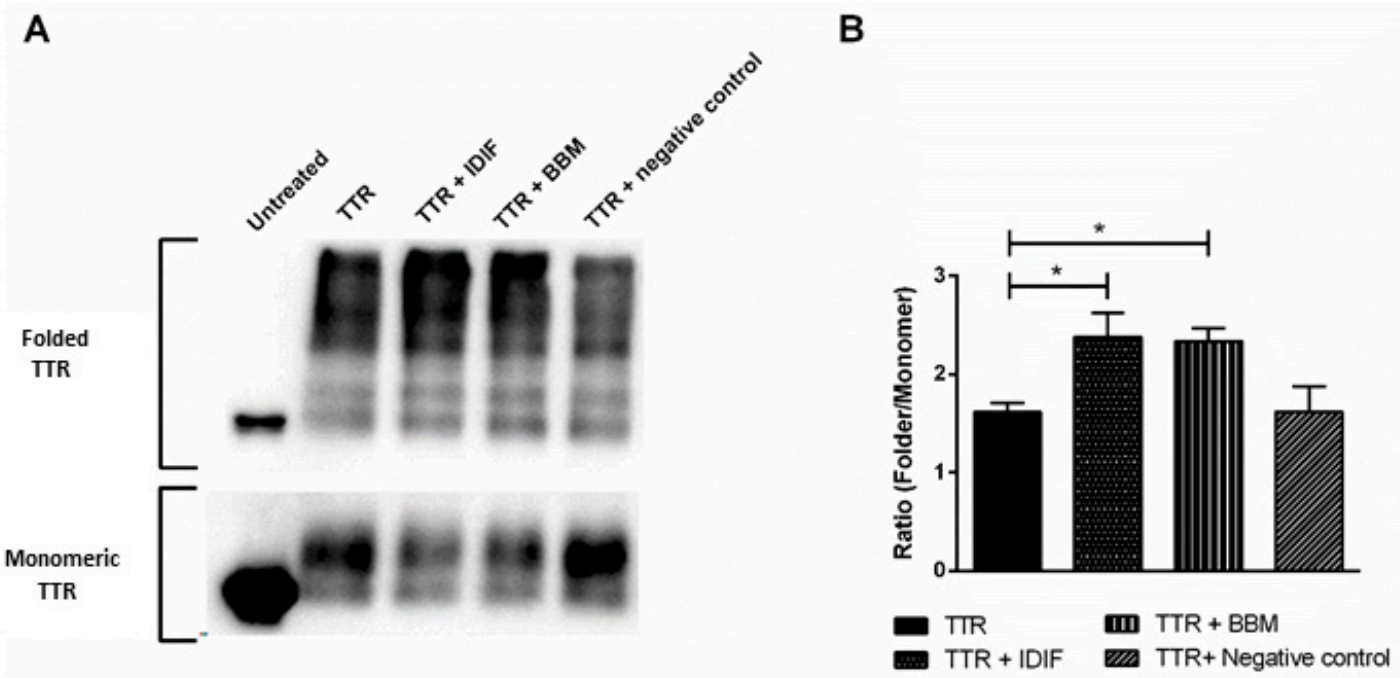

Figure 2. TTR resistance to urea denaturation. (A) TTR, alone or pre-incubated with different compounds, was subjected to urea denaturation, as described, and the generated species were detected by western blot. Incubation with iododiflunisal (IDIF) and benzbromarone (BBM) resulted in increased folded TTR, as compared to the negative control and TTR alone. (B) Quantification of results from three independent experiments. Error bars represent SEM. ${ }^{*} p<0.05$.

\subsection{Benzbromarone (BBM) Binds TTR in the T4 Central Binding Pocket}

We then investigated if the capacity of BBM to stabilize TTR was related to its binding in the T4-binding channel, as for the other TTR stabilizers mentioned. In this qualitative assay, we used human plasma as the source of TTR and measured the degree of ${ }^{125} \mathrm{I}-\mathrm{T} 4$ displacement by evaluating the decrease in the intensity of the TTR/ ${ }^{125} \mathrm{I}-\mathrm{T} 4$ band. As shown in Figure 3, BBM completely displaced T4 from TTR, similarly to IDIF. The negative control (sulfaquinoxaline) did not displace T4 from TTR and thus the intensity of the TTR/T4 band was similar to the one observed for TTR incubated in the absence of stabilizer. 


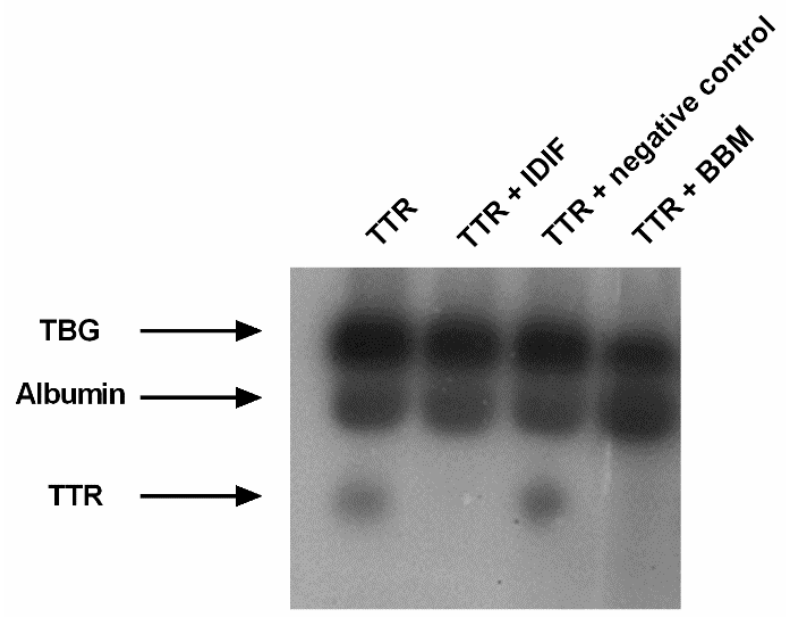

Figure 3. T4 displacement from TTR. Native gel electrophoresis of human plasma, incubated with ${ }^{125} \mathrm{I}-\mathrm{T} 4$ and competitor, showing that IDIF and BBM can compete with T4 for its binding site, whereas the negative control could not displace T4 from TTR. The migration of the different plasma T4-binding proteins is indicated.

As for the selectivity of BBM displacement of T4, with other proteins, BBM mainly displaced T4 from TTR, although it was possible to observe a small decrease in the intensity of the TBG/T4 bands and increase in the albumin/T4 bands (Figure 3).

To characterize the TTR/BBM interaction, and since the T4 displacement gel approach is only qualitative, we quantified the interaction using competition assays as described in the Materials and Methods (Figure 4A), and calculated the EC50 for each compound. The relative potency for the inhibition of the binding of T4 was defined as the ratio of (EC50 T4)/(EC50 small molecule) (Figure 4B). The results demonstrated that BBM had a high relative inhibition potency (1.06) similar to that of IDIF (0.96), prompting BBM as a potent TTR stabilizer. The negative control did not compete with T4 for TTR binding.

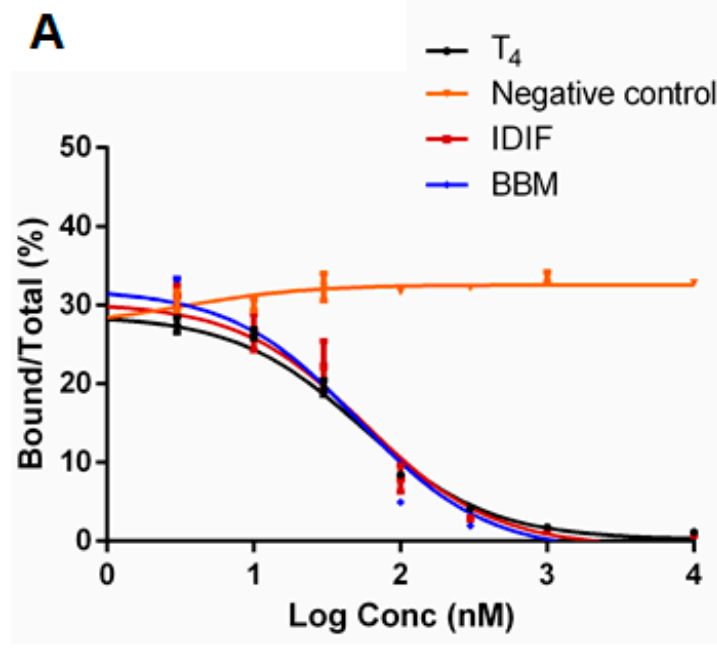

B

\begin{tabular}{|c|c|}
\hline Compound & $\begin{array}{c}\mathrm{EC}_{50} \mathrm{~T} 4 / \mathrm{EC}_{50} \\
\text { compound }\end{array}$ \\
\hline $\mathrm{T}_{4}$ & 1 \\
\hline Negative control & - \\
\hline IDIF & 0.96 \\
\hline BBM & 1.06 \\
\hline
\end{tabular}

Figure 4. (A) Displacement of ${ }^{125} \mathrm{I}-\mathrm{T} 4$ from TTR by competition with the compounds IDIF and BBM, the natural ligand T4 is used as a positive control and sulfaquinoxaline is used as a negative control; (B) relative potency for the inhibition of binding of $\mathrm{T} 4$. 
2.3. Isothermal Titration Calorimetry (ITC) Studies of the Binary Interaction between TTR and the Small-Molecule Drug Benzbromarone (BBM). Comparison with other TTR Binary Interactions with Iododiflunisal (IDIF), Tolcapone and Tafamidis

ITC is one of the gold standard biophysical methods for the quantitative analysis of intermolecular interaction, providing the complete thermodynamic profile in terms of free energy $(\Delta \mathrm{G})$, enthalpy $(\Delta \mathrm{H})$, entropy $(\Delta S)$, binding constant $(\mathrm{Kd})$ and stoichiometry $(\mathrm{n})$ of the interaction from a single experiment [40]. The Kd for the binding of a stabilizer to TTR is represented by the change in the Gibbs free energy of binding $(\Delta G)$, where $\Delta G=\Delta H-T \Delta S$. This technique has been used previously to compare small-molecule TTR stabilizers, like the small-molecule AG10 with other TTR tetramer stabilizer drugs [41].

ITC studies were performed to characterize the thermodynamic profile of the BBM binding to TTR. In this work, we compared the thermodynamic signatures of the interactions of TTR with other stabilizers, our lead compound IDIF and the TTR tetramer stabilizer drugs tolcapone and tafamidis (Figure 5).
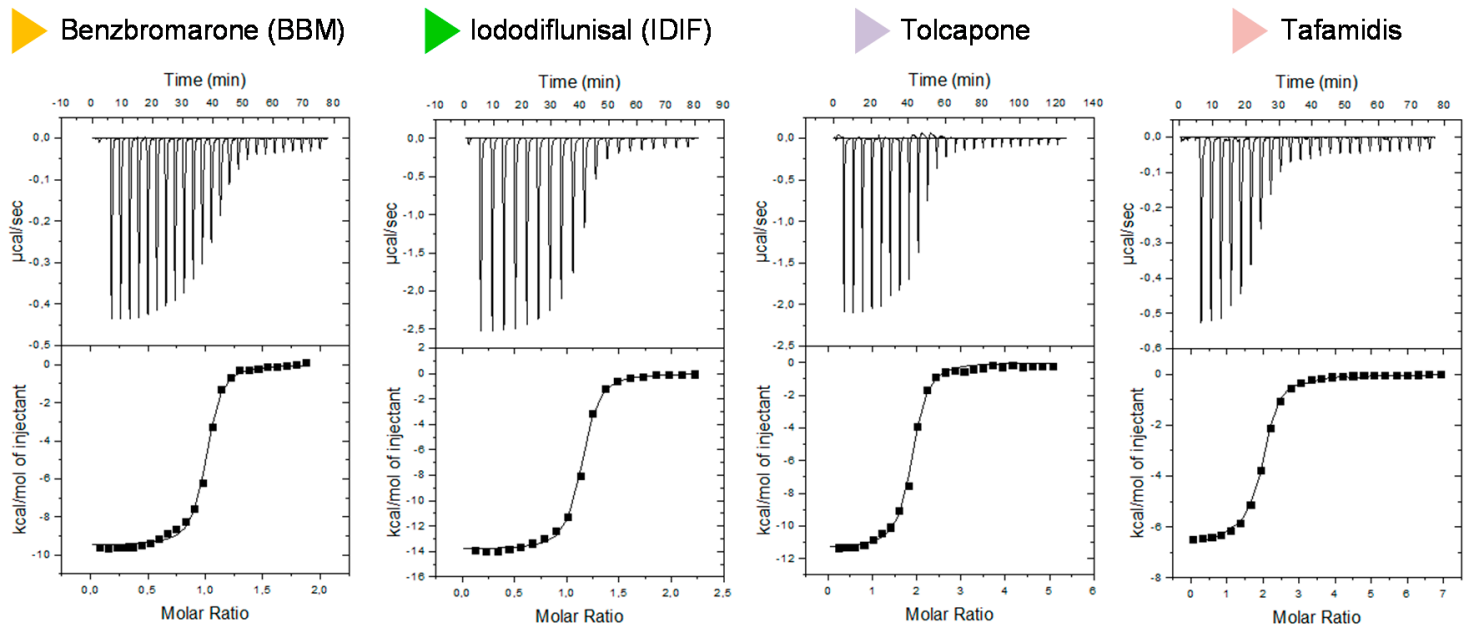

Figure 5. Thermograms of different complexes between TTR and small-molecule compounds: TTR + BBM, TTR + IDIF, TTR + tolcapone and TTR + tafamidis.

As it can be observed (Table 1), the binding stoichiometry number $\mathrm{n}$ is 1 both for BBM and for IDIF, whereas for tolcapone and tafamidis, $\mathrm{n}$ is 2 . The Kd values reported in Table 1 were based on data fitted to an independent single-site binding model implemented in Origin 7.0 (OriginLab). Previous ITC studies for the binary complexes of tolcapone and tafamidis with TTR have used either a single model [42] or a two-site model to approximate binding to TTR [24,41].

Table 1. Thermodynamic parameters for interaction of TTR with small-molecule compounds including some TTR stabilizer drugs analyzed by ITC.

\begin{tabular}{cccccc}
\hline Assay & $\mathbf{n}$ & $\mathbf{K d ~ ( n M )}$ & $\boldsymbol{\Delta} \mathbf{G}(\mathbf{K c a l} / \mathbf{m o l})$ & $\boldsymbol{\Delta} \mathbf{H}(\mathbf{K c a l} / \mathbf{m o l})$ & $\mathbf{T} \mathbf{\Delta S}(\mathbf{K c a l} / \mathbf{m o l})$ \\
\hline wtTTR + BBM & 1 & 60 & -9.93 & -9.94 & -0.02 \\
wtTTR + IDIF & 1 & 120 & -9.49 & -13.10 & -3.61 \\
wtTTR + tafamidis & 2 & 200 & -9.16 & -6.50 & 2.66 \\
wtTTR + tolcapone & 2 & 270 & -8.98 & -12.30 & -3.36 \\
wtTTR + diflunisal & 1 & 900 & -8.25 & -11.96 & -3.70 \\
\hline
\end{tabular}

The binding interactions for BBM with TTR are enthalpy driven $(\Delta \mathrm{H}=-9.93 \mathrm{kcal} / \mathrm{mol})$, similar to the binding interactions of our lead compound IDIF with TTR, but in the case of IDIF, the enthalpic contrition is higher $(\Delta \mathrm{H}=-13.10 \mathrm{kcal} / \mathrm{mol})$. BBM binds to TTR with a slightly unfavorable entropy contribution $(\mathrm{T} \Delta \mathrm{S}=-0.02 \mathrm{kcal} / \mathrm{mol})$ compared to the unfavorable entropy contribution $(\mathrm{T} \Delta S=-3.61 \mathrm{kcal} / \mathrm{mol})$ of 
IDIF. BBM shows similar binding affinities to TTR in buffer (i.e., similar $\Delta \mathrm{G}$ values) compared to IDIF, tolcapone and tafamidis. These ITC results confirm that BBM is a potent binder of TTR.

\subsection{Crystal Structure of TTR in Complex with BBM (TTR:BBM Complex)}

X-ray analysis was conducted to elucidate the molecular details of the interactions of BBM with TTR. Crystals of TTR in complex with BBM diffracted to a maximum of $1.35 \AA$ (see Supporting Information Table S1).

The two dimers that form TTR are related by a crystallographic 2-fold axis that runs along a central channel. The channel displays two hormone-binding sites, $\mathrm{AA}^{\prime}$ and $\mathrm{BB}^{\prime}$, with similar topology. BBM molecules bind deeply within the thyroxine binding pocket, with bromine atoms at the inner side of the cavity (Figure 6). In the crystal structure of the apo-TTR, Ser117 side chains face the cavities and hydrogen bonded to crystallographic water molecules. BBM binding induces the rotation of the side residues of serine 117 of all four monomers, prompting the formation of strong intermonomer hydrogen bonds which presumably increase the stability of the TTR tetramer.
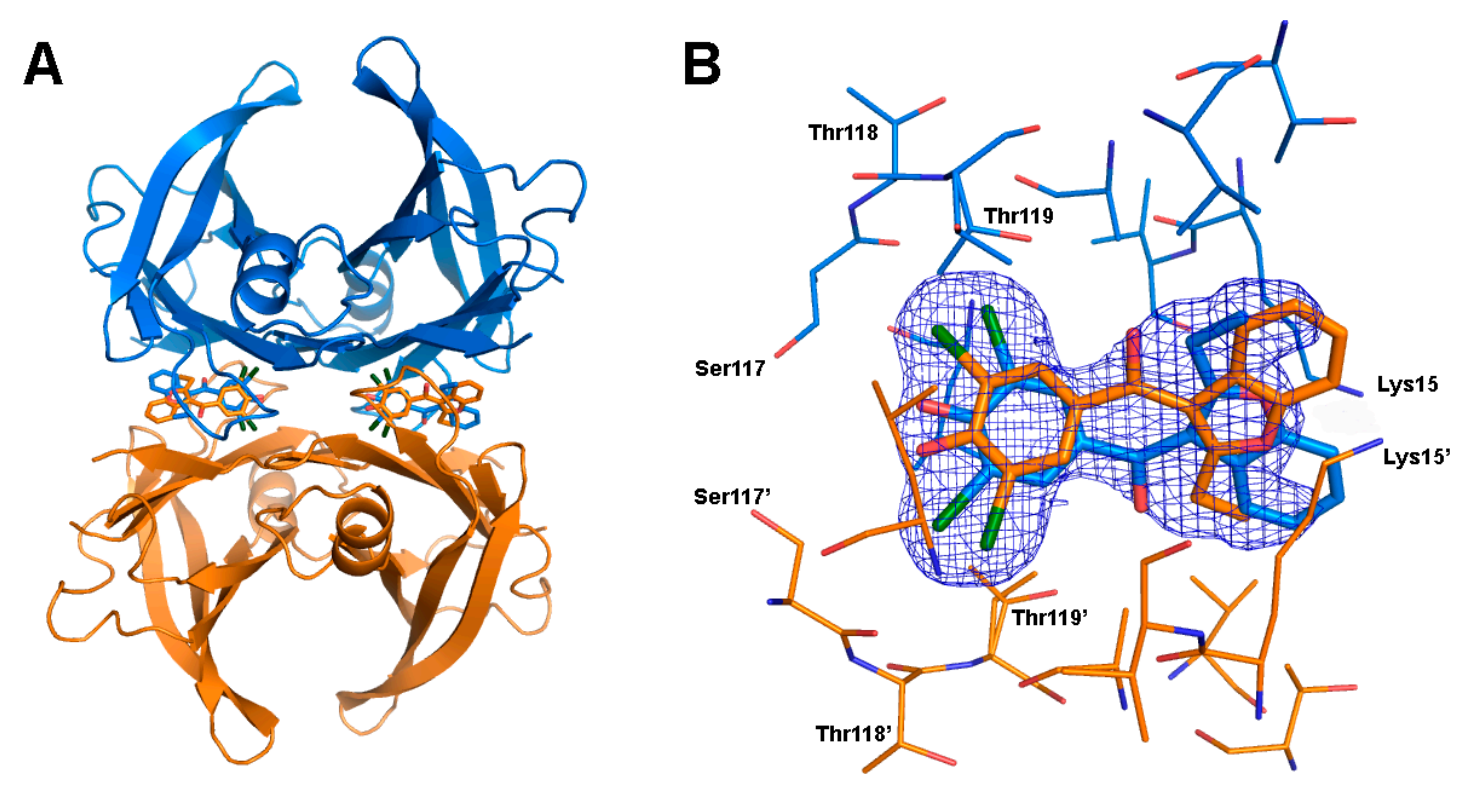

Figure 6. (A). Crystal structure of TTR in complex with benzbromarone (BBM). Monomers A and B and their symmetry-related pair (shown in light blue and brown) form a cavity in the dimer interface that can simultaneously accommodate two BBM molecules. (B) Close-up view of the BB' binding site, showing the two symmetry-related positions of BBM. 2Fo-Fc map (blue mesh) contoured around BBM at $1.0 \sigma$. Bromine atoms in green; oxygen in red; nitrogen in dark blue.

Three pairs of symmetry-related binding pockets (HBP1 and HBP1', HBP2 and HBP2', HBP3 and $\mathrm{HBP}^{\prime}$ ) are found within each hormone-binding pocket according to the positions of the iodine atoms of T4, when bound to TTR. BBM binds TTR in forward mode (Figure 7), with the bromine-substituted ring occupying the innermost part of the $\mathrm{T}_{4}$ binding site. The two bromine atoms are anchored in HBP3', comprising the side chains of Ser117', Leu110', Thr119' and Ala108', and in HBP2, comprising residues Leu17, Ala108, Ala109 and Leu110, respectively. Ligand binding induces the rotation of the side chains of Ser117 residues of the four monomers, leading to the formation of strong intermonomer hydrogen bonds. 


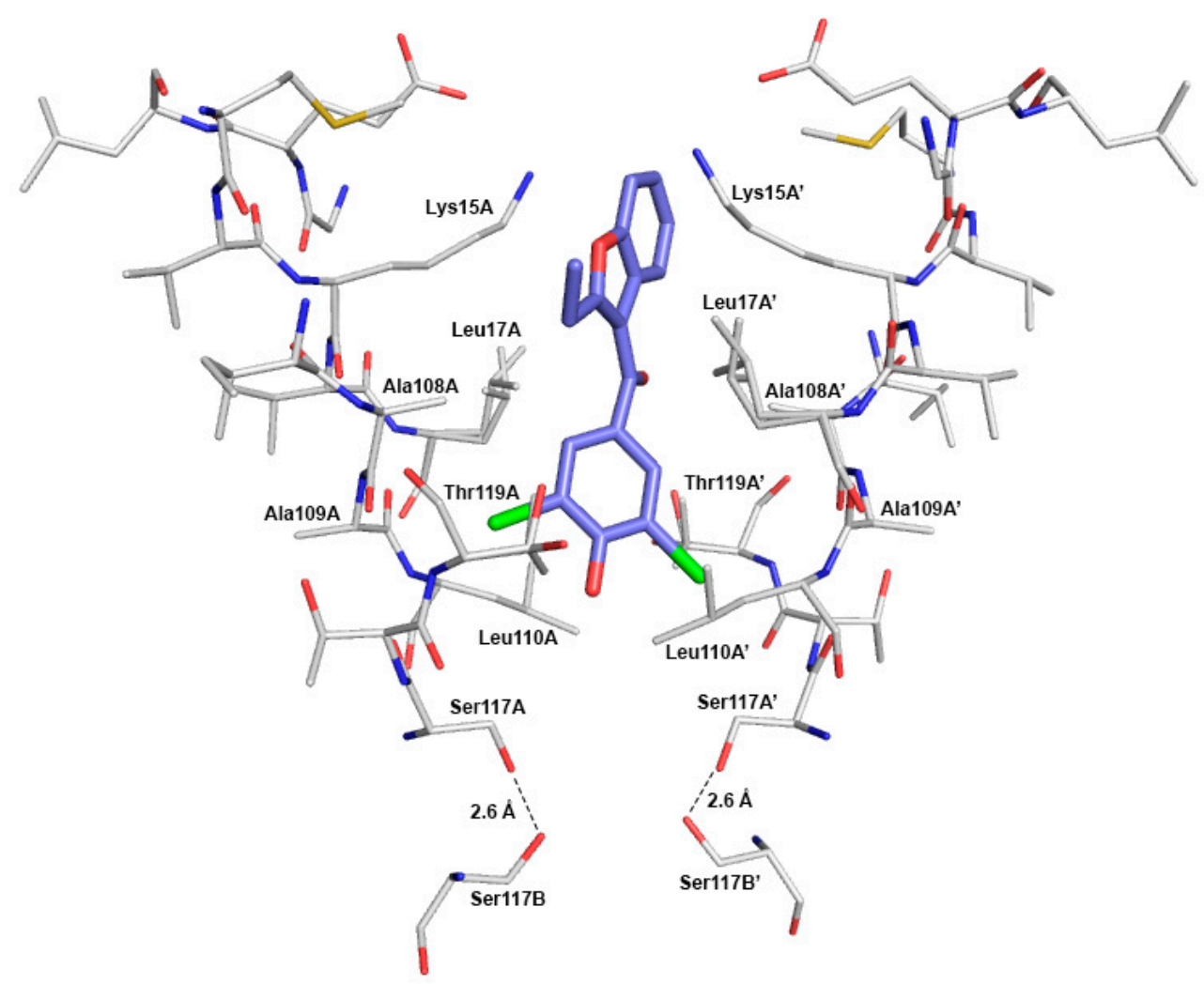

Figure 7. Close view of the interactions of benzbromarone (BBM) with the TTR AA' binding site (carbon atoms in grey, nitrogen atoms in dark blue, oxygen in red, sulfur in dark yellow and bromine atoms of $\mathrm{BBM}$ in green).

The binding mode of BBM to TTR is very similar to the one of the abovementioned TBBPA. Nevertheless, superposition of the two crystals structures reveals that BMM binds slightly deeper than TBBPA (Figure 8).

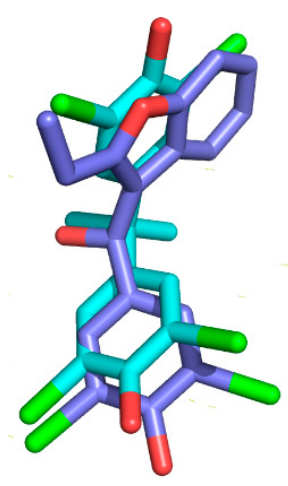

Figure 8. Close superposition of TTR AA' binding site of the complexes of TTR with BBM and with TBBPA (PDB ID: 5HJG). Only the ligands are shown to highlight the similarities of their binding modes. The orientation of the protein binding site is similar to the one in Figure 7. BBM and TBBPA atom colors as in Figure 7 except for TBBPA carbon atoms shown in light blue.

\subsection{Comparative Analysis of the Ability of BBM to Inhibit TTR Fibrillogenesis at Acidic $p H$}

Finally, to investigate the impact of BBM on TTR aggregation, we determined the effect of BBM on the aggregation of the amyloidogenic Y78F hTTR mutant, by using our kinetic assay [43] that follows turbidimetry of TTR at $340 \mathrm{~nm}$ (Figure 9A), and performed a comparative analysis with other TTR stabilizers, such as tafamidis (Figure 9B), tolcapone (Figure 9D) and IDIF (Figure 9C). 
A

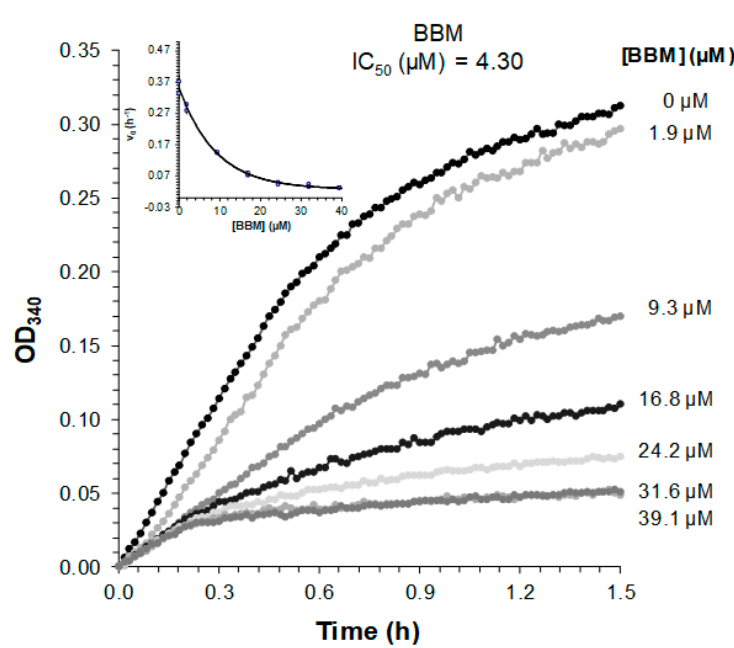

C

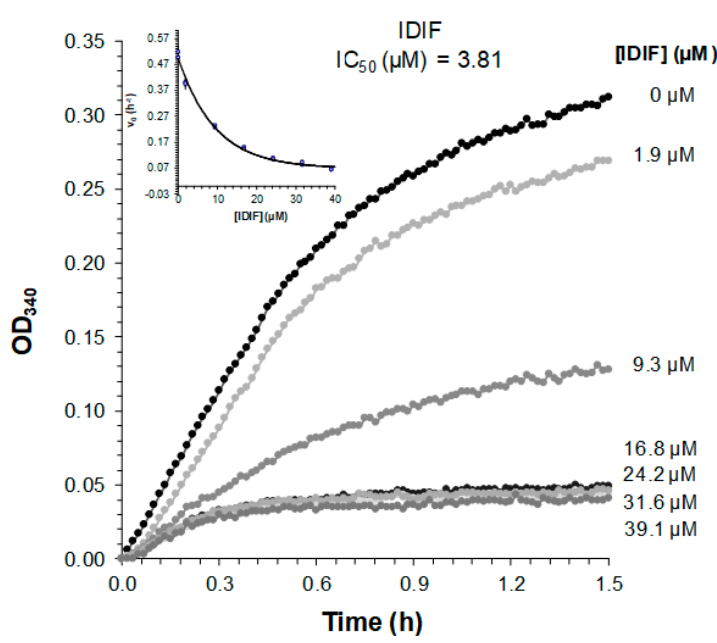

B

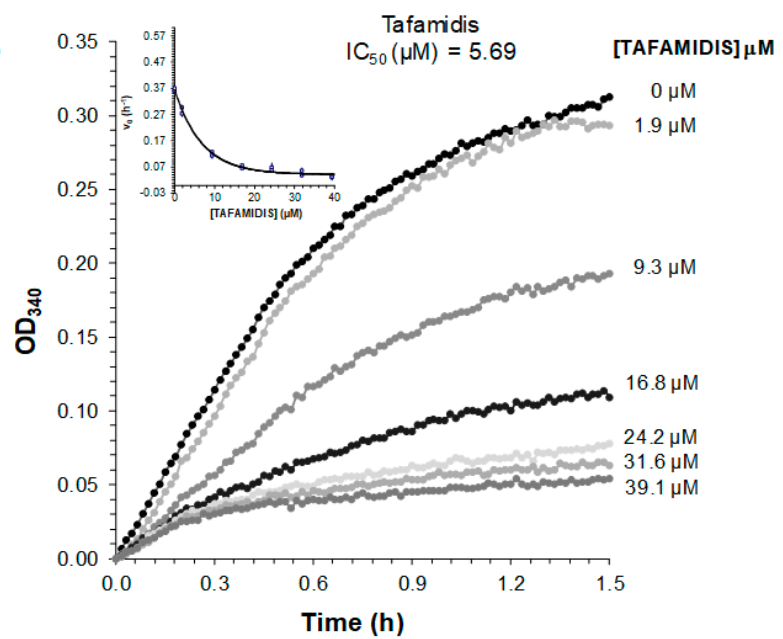

D

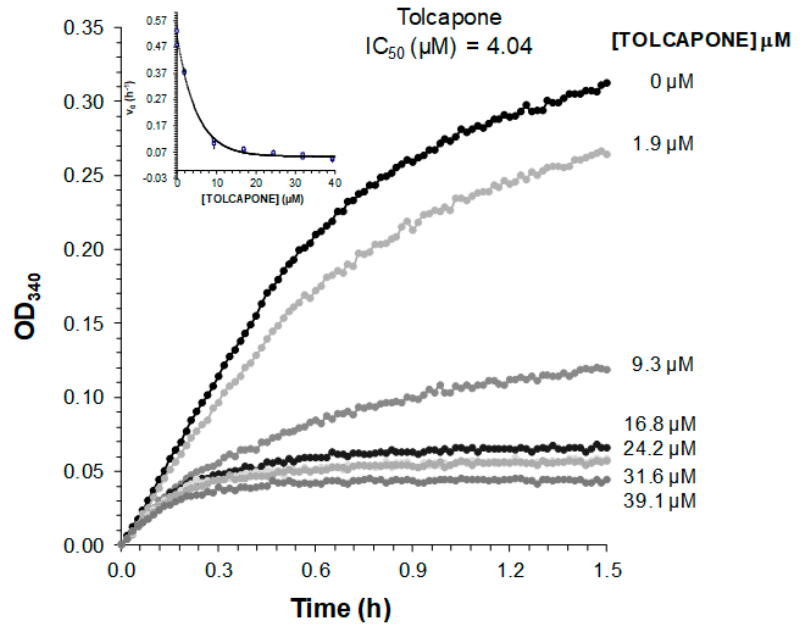

Figure 9. Time course of Y78F hTTR fibril formation at $\mathrm{pH} 4.2,37^{\circ} \mathrm{C}$ in the presence of different concentrations of: (A) BBM (inset: plot of initial rates of fibril formation (V0) vs. BBM concentration (Figure S1). Data were fitted to eq 1); (B) tafamidis (inset: plot of initial rates of fibril formation vs. tafamidis concentration) (Figure S2); (C) IDIF (inset: plot of initial rates of fibril formation vs. IDIF concentration) (Figure S4); and (D) tolcapone (inset: plot of initial rates of fibril formation vs. tolcapone concentration) (Figure S3).; for diflunisal (Figure S5); as monitored by absorbance at $340 \mathrm{~nm}$ at different concentrations. Experiments were performed in duplicate.

Kinetic measurements showed that BBM efficiently prevents the aggregation of Y78F hTTR at low $\mathrm{pH}$, with $\mathrm{IC}_{50}=4.30 \mu \mathrm{M}$, in the same order as the $\mathrm{IC}_{50}$ for our small-molecule IDIF $\left(\mathrm{IC}_{50}=3.81 \mu \mathrm{M}\right)$ and the ones for the drugs tafamidis $\left(\mathrm{IC}_{50}=5.69 \mu \mathrm{M}\right)$ and tolcapone $\left(\mathrm{IC}_{50}=4.05 \mu \mathrm{M}\right)$.

\section{Materials and Methods}

\subsection{Compounds}

Tafamidis was synthesized in our laboratory according to reported procedures in the literature [44]. HEPES, N-(2-Hydroxyethyl) piperazine- $N^{\prime}$-(2-ethanesulfonic acid); glycine; dimethyl sulfoxide (DMSO), the NSAID drug diflunisal (DIF) and the drug tolcapone were commercially available from Sigma-Aldrich (St. Louis, MO, USA). Iododiflunisal (IDIF) was prepared in our lab by iodination 
of the NSAID diflunisal, following our previously described procedures [28]. Purity of all compounds was proved to be $\geq 95 \%$ by means of analytical HPLC, NMR and UPLC-TOF-MS techniques.

\subsection{TTR Production and Purification}

Human recombinant wild-type TTR (wt TTR) and the mutant Y78F (Y78F hTTR) were produced in a bacterial expression system using Escherichia coli BL21 [45] and purified as previously described [46]. Briefly, after growing the bacteria, the protein was isolated and purified by preparative gel electrophoresis after ion exchange chromatography. Protein concentration was determined by the Bradford method (Bio-Rad, Hercules, CA, USA), using bovine serum albumin (BSA) as standard.

\subsection{TTR Stability Assay}

Recombinant wtTTR was incubated alone or in the presence of different compounds: IDIF as a reference positive control, the veterinary drug sulfaquinoxaline as a negative control, and the BBM drug at a molar ratio of $1: 10$ (TTR:drug) for $1 \mathrm{~h}$ at $37^{\circ} \mathrm{C}$. Then, urea was added at $6 \mathrm{M}$ and samples were further incubated at $37^{\circ} \mathrm{C}$, overnight. The cross-linking reaction was performed by adding $2.5 \%$ glutaraldehyde for $4 \mathrm{~min}$ and then the reaction was quenched by adding $0.1 \%$ sodium borohydride. Samples were then run in a 13.5\% acrylamide gel prepared with SDS, and transferred onto a nitrocellulose membrane (Amersham NC Protran ${ }^{\mathrm{TM}} 0.2 \mu \mathrm{m}$ Amersham GE Healthcare, Buckinghamshire, UK) using a wet system (Bio-Rad Criterion Blotter). The membranes were blocked for $1 \mathrm{~h}$ at RT with $5 \%$ nonfat dry milk (DM) in PBS containing 0.05\% Tween-20 (PBS-T) and then incubated with primary antibody antihuman TTR (Dako; 1:1000 in 3\% DM/PBS-T, Dako, Glostrup, Denmark). Then, washed membranes were incubated for $1 \mathrm{~h}$ at RT with sheep antirabbit immunoglobulins conjugated with horseradish peroxidase (Binding Site; 1:5000 in 3\% DM/PBS-T). The blots were developed using Clarity ${ }^{\mathrm{TM}}$ Western ECL substrate (Bio-Rad), and levels of folded (tetramer + trimer + dimer) and monomeric TTR were detected and visualized using a chemiluminescence detection system (ChemiDoc, Bio-Rad).

\subsection{Thyroxine Binding Assays}

Qualitative studies of the displacement of T4 from TTR were carried out by incubation of $5 \mu \mathrm{L}$ of human plasma, with ${ }^{125} \mathrm{I}-\mathrm{T} 4$ (specific radioactivity $\approx 1200 \mu \mathrm{Ci} / \mu \mathrm{g}$; Perkin Elmer) in the presence of the different compounds (IDIF, BBM and sulfaquinoxaline) at a final concentration of $666 \mu \mathrm{M}$. Protein separation was carried in a native PAGE system using glycine/acetate buffer. The gel was dried and revealed using an X-ray film.

For the quantitative analysis, $\mathrm{T}_{4}$ binding competition assays based on a gel filtration procedure were used, as previously described [47]. Briefly, $30 \mathrm{nM}$ human recombinant wtTTR was incubated with cold T4 or compound (IDIF, BBM and sulfaquinoxaline negative control) solutions of variable concentrations ranging from 0 to $1000 \mathrm{nM}$ and with a constant amount of labeled ${ }^{125} \mathrm{I}-\mathrm{T} 4(\sim 50,000 \mathrm{cpm})$. This solution was counted in a gamma spectrometer and incubated at $4{ }^{\circ} \mathrm{C}$ overnight. Protein-bound ${ }^{125} \mathrm{I}-\mathrm{T} 4$ and free ${ }^{125} \mathrm{I}-\mathrm{T} 4$ were separated by gel filtration through a $1 \mathrm{~mL}$ BioGel P6DG (Bio-Rad, Hercules, CA, USA) column. The bound fraction was eluted while free T4 was retained on the BioGel matrix. The eluate containing the bound T4 was collected and counted. Bound T4 was expressed as a percentage of total T4 added. The experiment was performed twice, and each assay was done in duplicate. Analysis of the binding data was performed with the GraphPad Prism program (version 5.0, San Diego, CA, USA) and data were expressed as the ratio of $\mathrm{EC}_{50} \mathrm{~T} 4 / \mathrm{EC}_{50}$ compound.

\subsection{Isothermal Titration Calorimetry (ITC) Studies}

Isothermal titration calorimetry (ITC) measurements were carried out in a VP-ITC (MicroCal, LLC, Northampton, MA, USA). In a titration experiment, the ligand in the syringe is added in small aliquots to the TTR protein in the calorimeter cell, which is filled with an effective volume that is sensed calorimetrically. All solutions, either TTR protein or drugs, were prepared in $25 \mathrm{mM}$ HEPES buffer, $10 \mathrm{mM}$ glycine, $\mathrm{pH} 7.4$ and 5\% DMSO (final concentration). The concentration of TTR solution was 
5-10 $\mu \mathrm{M}$ and 50-100 $\mu \mathrm{M}$ for ligand solutions. All solutions were filtered and degassed prior to usage. The TTR protein solution was injected over 20 or 30 times at a constant interval of $300 \mathrm{~s}$ with a $450 \mathrm{rpm}$ rotating stirrer syringe into the sample cell. In the control experiment, the ligand was injected into the buffer in the sample cell to obtain the heat of dilution. The value of the heat of dilution was subtracted from the experimental result in the final analysis. The experiments were performed at $25^{\circ} \mathrm{C}$, reference power at 10. Titration data were analyzed by the evaluation software, MicroCal Origin, Version 7.0, provided by the manufacturer. Calorimetric data were plotted and fitted using the standard single-site binding model. The binding curves were fitted to the calculations of the parameters' stoichiometry $(\mathrm{n})$, dissociation constant $(\mathrm{Kd})$ and the changes in the enthalpy $(\Delta \mathrm{H})$, entropy $(\Delta \mathrm{S})$ and Gibbs free energy $(\Delta \mathrm{G})$ during the complex formation. Each experiment was done three times.

\subsection{Co-Crystallization}

The wtTTR at $182 \mu \mathrm{M}$ was incubated with BBM (molar ratio BBM/wtTTR $=13$ ) at $4{ }^{\circ} \mathrm{C}$ for $16 \mathrm{~h}$, in $10 \mathrm{mM}$ HEPES buffer, $\mathrm{pH}$ 7.5. Crystals suitable for X-ray diffraction were obtained by the hanging-drop vapor-diffusion technique at $20^{\circ} \mathrm{C}$ and were grown within 2 weeks by mixing $2 \mu \mathrm{L}$ of the protein:BBM solution with $2 \mu \mathrm{L}$ of reservoir solution. The reservoir solution contained $0.2 \mathrm{M}$ acetate buffer $\mathrm{pH}$ 4.8, 2.2 M ammonium sulfate and 7\% glycerol. Crystals were transferred to reservoir solutions containing increasing concentrations of glycerol (10-25\%) and flash frozen in liquid nitrogen.

\subsection{X-Ray Diffraction Data Collection, Processing and Structure Refinement}

X-ray diffraction data sets were collected using synchrotron radiation $(\lambda=0.979 \AA)$ at the Proxima 1 beam line of the SOLEIL synchrotron (Paris, France). Preliminary data were measured in ESRF and ALBA synchrotrons. A summary of the data collection and refinement statistics is presented in Table S1 in the Supporting Information. Diffraction images were processed with the iMosflm software [48] and the scaling and merging of the reflections were performed using programs SCALA and TRUNCATE [49]. A random 5\% sample of the reflection data was flagged for R-free calculations [50] during model building and refinement. Initial molecular replacement phases were generated with Phaser MR [51], using as the initial model one monomer of the complex TTR:IDIF (PDB ID: 1Y1D) [27] followed by refinement cycles performed with Refmac5 [49]. The final models were obtained after further cycles of manual model building and refinement, carried out with Coot [52] and PHENIX [53], respectively. Structural data were deposited in the Protein Data Bank (PDB) with PDB ID code 7ACU and figures of the protein model were generated with PyMol [54].

\subsection{Kinetic Turbidity Assay}

Protein (Y78F hTTR) stock: $4 \mathrm{mg} / \mathrm{mL}$ in $20 \mathrm{mM}$ phosphate, $100 \mathrm{mM} \mathrm{KCl}$, $\mathrm{pH}$ 7.6. Incubation buffer: $10 \mathrm{mM}$ phosphate, $100 \mathrm{mM} \mathrm{KCl}, 1 \mathrm{mM}$ EDTA, pH 7.6. Dilution buffer: $400 \mathrm{mM}$ sodium acetate, $100 \mathrm{mM}$ $\mathrm{KCl}, 1 \mathrm{mM}$ EDTA, pH 4.2. Protocol for one compound: $20 \mu \mathrm{L}$ of Y78F hTTR stock was dispensed into seven wells of a 96-well microplate. Different volumes of working inhibitor solution were added to give final concentrations ranging from 0 to $40 \mu \mathrm{M}$, and the final DMSO content of each well was adjusted to $5 \%$ by adding the corresponding volume of a $\mathrm{H} 2 \mathrm{O} / \mathrm{DMSO}$ (1:1) solution. Incubation buffer was then added up to a volume of $100 \mu \mathrm{L}$. The plate was incubated at $37^{\circ} \mathrm{C}$ in a thermostated microplate reader with orbital shaking $15 \mathrm{~s}$ every minute for $30 \mathrm{~min}$. A $100 \mu \mathrm{L}$ portion of dilution buffer was dispensed to each well, and the mixture was incubated at $37^{\circ} \mathrm{C}$ with shaking ( $15 \mathrm{~s}$ every $\mathrm{min}$ ) in the microplate reader. Absorbance at $340 \mathrm{~nm}$ was monitored for $1.5 \mathrm{~h}$ at $1 \mathrm{~min}$ intervals. Data were collected and analyzed using Microsoft Excel software. All assays were done in duplicate.

\subsection{Statistics}

The data are presented as means \pm SEM and were analysed by the unpaired Student's $t$-test using GraphPad Prism 8 software for Windows (GraphPad, San Diego, CA, USA), and those showing a $p$-value $<0.05$ were considered significant. 


\section{Conclusions}

We have shown that BBM stabilizes the TTR tetramer and in vitro and ex vivo approaches demonstrated that the binding occurs in the T4-binding pocket, with a capacity similar to IDIF, tafamidis and tolcapone, known as strong TTR stabilizers. A full characterization of the thermodynamic profile by ITC studies showed that the BBM enthalpically driven mode of action is through kinetic stabilization of TTR, with similar profiles to tafamidis and tolcapone.

The analysis of the crystal structure shows that BBM binds TTR in forward mode, with the bromine-substituted ring occupying the innermost part of the T4-binding site. BBM binding induces the rotation of the side residues of serine 117 of all four monomers, prompting the formation of strong intermonomer hydrogen bonds, which presumably increase the stability of the TTR tetramer.

Importantly, by a comparative kinetic analysis of the inhibition of TTR fibrillogenesis at moderately acid $\mathrm{pH}$, we have concluded that BBM has similar inhibitory potency as known TTR stabilizer drugs.

On the basis of the obtained results, we can conclude that the uricosuric drug benzbromarone (BBM) presents an interesting scaffold in the quest to design of new and improved TTR stabilizers. Further studies are in progress to evaluate if this drug can be repurposed for FAP.

Supplementary Materials: Supplementary Materials can be found at http://www.mdpi.com/1422-0067/21/19/ 7166/s1. Data collection and refinement statistics; kinetics of aggregation of TTR in the presence of different stabilizers; list of organohalogen compounds among the TTR $\mathrm{T}_{4}$ tetramer stabilizers reported in PDB.

Author Contributions: E.Y.C.: Data curation (turbidimetry/kinetics). E.Y.C., Â.O. and J.P.L.: Writing一original draft preparation. Â.O.: Data curation (T4 binding assays; TTR stability assays). J.P.L.: Data curation (X-ray). J.L.: conceptualization, Writing-reviewing and editing. L.G.: Conceptualization (X-ray), methodology (X-ray), writing-reviewing. J.Q. and I.C.: Conceptualization, methodology, writing-reviewing and editing. G.A.: Conceptualization, methodology, writing-reviewing and editing. All authors have read and agreed to the published version of the manuscript.

Funding: I.C. works under the Investigator FCT Program which is financed by national funds through FCT and co-financed by ESF through HPOP, type 4.2, Promotion of Scientific Employment. I.C. acknowledges a grant from Fundação Millennium bcp. G.A. acknowledges a grant from Fundació Marató de TV3, Spain (project ref. 20140330-31-32-33-34) and from Spanish MINECO (grant CTQ2016-76840-R).

Acknowledgments: E.Y.C. acknowledges a contract funded by the project of Fundació Marató de TV3, Spain (project ref. 20140330-31-32-33-34) and a contract from Ford España-Fundación Apadrina la Ciencia. J.P. Leite acknowledges the FCT PhD fellowship SFRH/BD/129921/2017 (Portugal). G.A. acknowledges Rafel Prohens from Unitat de Polimorfisme i Calorimetria, Centres Científics i Tecnològics (University of Barcelona) for his supervision and assistance in ITC studies and acknowledges Antoni Planas (IQS-URL) for full support on the TTR production. We would also like to thank the SOLEIL (Essonne, France) beam line staff for the assistance during data collection, as well as the staff of the ESRF (France) and ALBA (Barcelona, Spain) synchrotrons for assistance in the collection of preliminary data.

Conflicts of Interest: The authors declare no conflict of interest.

\section{Abbreviations}

$\begin{array}{ll}\text { AD } & \text { Alzheimer's disease } \\ \text { BBM } & \text { Benzbromarone } \\ \text { BSA } & \text { Bovine serum albumin } \\ \text { COMT } & \text { Catechol-O-methyltransferase } \\ \text { CSF } & \text { Cerebrospinal fluid } \\ \text { DIF } & \text { Diflunisal } \\ \text { DM } & \text { Dried milk } \\ \text { DMSO } & \text { Dimethyl sulfoxide } \\ \text { ECL } & \text { Enhanced chemiluminescence } \\ \text { EDTA } & \text { Ethylenediaminetetraacetic acid } \\ \text { FAP } & \text { Familial amyloid polyneuropathy } \\ \text { HBP } & \text { Halogen-binding pocket } \\ \text { HEPES } & N \text {-(2-Hydroxyethyl) piperazine- } N^{\prime} \text {-(2-ethanesulfonic acid) } \\ \text { HPLC } & \text { High-performance liquid chromatography }\end{array}$




$\begin{array}{ll}\text { IDIF } & \text { Iododiflunisal } \\ \text { ITC } & \text { Isothermal titration calorimetry } \\ \text { NMR } & \text { Nuclear magnetic resonance } \\ \text { NSAID } & \text { Non-steroidal anti-inflammatory drug } \\ \text { PBP } & \text { Pentabromophenol } \\ \text { PBS } & \text { Phosphate-buffered saline } \\ \text { PDB } & \text { Protein Data Bank } \\ \text { rpm } & \text { revolutions per minute } \\ \text { RT } & \text { Room temperature } \\ \text { SDS } & \text { Sodium dodecyl sulphate } \\ \text { TBBPA } & \text { Tetrabromobisphenol A } \\ \text { T4 } & \text { Thyroxine } \\ \text { TBG } & \text { Thyroxine-binding globulin } \\ \text { TTR } & \text { Transthyretin } \\ \text { UPLC-TOF-MS } & \text { Ultra-high performance liquid chromatography time of flight mass spectrometry }\end{array}$

\section{References}

1. Blake, C.C.; Geisow, M.J.; Oatley, S.J.; Rerat, B.; Rerat, C. Structure of prealbumin: Secondary, tertiary and quaternary interactions determined by Fourier refinement at $1.8 \AA$ A. J. Mol. Biol. 1978, 121, 339-356. [CrossRef]

2. Hamilton, J.A.; Benson, M.D. Transthyretin: A review from a structural perspective. Cell. Mol. Life Sci. 2001, 58, 1491-1521. [CrossRef] [PubMed]

3. Herbert, J.; Wilcox, J.N.; Pham, K.T.; Fremeau, R.T., Jr.; Zeviani, M.; Dwork, A.; Soprano, D.R.; Makover, A.; Goodman, D.S.; Zimmerman, E.A. Transthyretin: A choroid plexus-specific transport protein in human brain. The 1986 S. Weir Mitchell award. Neurology 1986, 36, 900-911. [CrossRef] [PubMed]

4. Monaco, H.L.; Rizzi, M.; Coda, A. Structure of a complex of two plasma proteins: Transthyretin and retinol binding protein. Science 1995, 268, 1039-1041. [CrossRef] [PubMed]

5. Zanotti, G.; Berni, R. Plasma retinol-binding protein: Structure and interactions with retinol, retinoids, and transthyretin. Vitam. Horm. 2004, 69, 271-295.

6. Hagen, G.A.; Elliott, W.J. Transport of thyroid hormones in serum and cerebrospinal fluid. J. Clin. Endocrinol. Metab. 1973, 7, 415-422. [CrossRef]

7. Gião, T.; Saavedra, J.; Cotrina, E.; Quintana, J.; Llop, J.; Arsequell, G.; Cardoso, I. Undiscovered Roles for Transthyretin: From a Transporter Protein to a New Therapeutic Target for Alzheimer's Disease. Int. J. Mol. Sci. 2020, 21, 2075. [CrossRef]

8. Schwarzman, A.L.; Gregori, L.; Vitek, M.P.; Lyubski, S.; Strittmatter, W.J.; Enghilde, J.J.; Bhasin, R.; Silverman, J.; Weisgraber, K.H.; Coyle, P.K.; et al. Transthyretin sequesters amyloid beta protein and prevents amyloid formation. Proc. Nat. Acad. Sci. USA 1994, 91, 8368-8372. [CrossRef]

9. Garai, K.; Posey, A.E.; Li, X.; Buxbaum, J.N.; Pappu, R.V. Inhibition of amyloid beta fibril formation by monomeric human transthyretin. Protein. Sci. 2018, 27, 1252-1261. [CrossRef]

10. Alemi, M.; Silva, S.C.; Santana, I.; Cardoso, I. Transthyretin stability is critical in assisting beta amyloid clearance-Relevance of transthyretin stabilization in Alzheimer's disease. CNS Neurosci. Ther. 2017, 23, 605-619. [CrossRef]

11. Adams, D.; Koike, H.; Slama, M.; Coelho, T. Hereditary transthyretin amyloidosis: A model of medical progress for a fatal disease. Nat. Rev. Neurol. 2019, 15, 387-404. [CrossRef] [PubMed]

12. Plante-Bordeneuve, V. Transthyretin familial amyloid polyneuropathy: An update. J. Neurol. 2018, 265, 976-983. [CrossRef] [PubMed]

13. Siddiqi, O.K.; Ruberg, F.L. Cardiac amyloidosis: An update on pathophysiology, diagnosis, and treatment. Trends Cardiovasc. Med. 2018, 28, 10-21. [CrossRef] [PubMed]

14. Westermark, P.; Sletten, K.; Johansson, B.; Cornwell, G.G., 3rd. Fibril in senile systemic amyloidosis is derived from normal transthyretin. Proc. Natl. Acad. Sci. USA 1990, 87, 2843-2845. [CrossRef]

15. Ziskin, J.L.; Greicius, M.D.; Zhu, W.; Okumu, A.N.; Adams, C.M.; Plowey, E.D. Neuropathologic analysis of Tyr69His TTR variant meningovascular amyloidosis with dementia. Acta Neuropathol. Commun. 2015, 3, 43. [CrossRef] 
16. Connelly, S.; Choi, S.; Johnson, S.M.; Kelly, J.W.; Wilson, I.A. Structure-based design of kinetic stabilizers that ameliorate the transthyretin amyloidoses. Curr. Opin. Struct. Biol. 2010, 20, 54-62. [CrossRef]

17. Berman, H.M.; Westbrook, J.; Feng, Z.; Gilliland, G.; Bhat, T.N.; Weissig, H.; Shindyalov, I.N.; Bourne, P.E. The Protein Data Bank. Nucleic Acids Res. 2000, 28, 235-242. [CrossRef]

18. Palaninathan, S.K. Nearly 200 X-Ray Crystal Structures of Transthyretin: What Do They Tell Us about This Protein and the Design of Drugs for TTR Amyloidoses? Curr. Med. Chem. 2012, 19, 2324-2342. [CrossRef]

19. Nencetti, S.; Orlandini, E. TTR fibril formation inhibitors: Is there a SAR? Curr. Med. Chem. 2012, 19, 2356-2379.

20. Guo, X.; Liu, Z.; Zheng, Y.; Li, Y.; Li, L.; Liu, H.; Chen, Z.; Wu, L. Review on the Structures and Activities of Transthyretin Amyloidogenesis Inhibitors. Drug Des. Devel. Ther. 2020, 14, 1057-1081. [CrossRef]

21. Wojtczak, A.; Cody, V.; Luft, J.; Pangborn, W. Structures of human transthyretin complexed with thyroxine at $2.0 \AA$ resolution and 3', 5'-dinitro-N-acetyl-L-thyronine at 2.2 ̊̊ resolution. Acta Crystallogr. D Biol. Crystallogr. 1996, 52, 758-765. [CrossRef] [PubMed]

22. Waddington Cruz, M.; Amass, L.; Keohane, D.; Schwartz, J.; Li, H.; Gundapaneni, B. Early intervention with tafamidis provides long-term (5.5-year) delay of neurologic progression in transthyretin hereditary amyloid polyneuropathy. Amyloid 2016, 23, 178-183. [CrossRef] [PubMed]

23. Berk, J.L.; Suhr, O.B.; Obici, L.; Sekijima, Y.; Zeldenrust, S.R.; Yamashita, T.; Heneghan, M.A.; Gorevic, P.D.; Litchy, W.J.; Wiesman, J.F.; et al. Diflunisal Trial Consortium. Repurposing diflunisal for familial amyloid polyneuropathy: A randomized clinical trial. JAMA 2013, 310, 2658-2667. [CrossRef] [PubMed]

24. Sant'Anna, R.; Gallego, P.; Robinson, L.Z.; Pereira-Henriques, A.; Ferreira, N.; Pinheiro, F.; Esperante, S.; Pallares, I.; Huertas, O.; Almeida, M.R.; et al. Repositioning tolcapone as a potent inhibitor of transthyretin amyloidogenesis and associated cellular toxicity. Nat. Commun. 2016, 7, 10787. [CrossRef]

25. Fox, J.C.; Hellawell, J.L.; Rao, S.; O’Reilly, T.; Lumpkin, R.; Jernelius, J.; Gretler, D.; Sinha, U. First-in-Human Study of AG10, a Novel, Oral, Specific, Selective, and Potent Transthyretin Stabilizer for the Treatment of Transthyretin Amyloidosis: A Phase 1 Safety, Tolerability, Pharmacokinetic, and Pharmacodynamic Study in Healthy Adult Volunteers. Clin. Pharmacol. Drug Dev. 2020, 9, 115-129. [CrossRef]

26. Almeida, M.R.; Macedo, B.; Cardoso, I.; Alves, I.; Valencia, G.; Arsequell, G.; Planas, A.; Saraiva, M.J. Selective binding to transthyretin and tetramer stabilization in serum from patients with familial amyloidotic polyneuropathy by an iodinated diflunisal derivative. Biochem. J. 2004, 381, 351-356. [CrossRef]

27. Gales, L.; Macedo-Ribeiro, S.; Arsequell, G.; Valencia, G.; Saraiva, M.J.; Damas, A.M. Human transthyretin in complex with iododiflunisal: Structural features associated with a potent amyloid inhibitor. Biochem. J. 2005, 388, 615-621. [CrossRef]

28. Mairal, T.; Nieto, J.; Pinto, M.; Almeida, M.R.; Gales, L.; Ballesteros, A.; Barluenga, J.; Pérez, J.J.; Vázquez, J.T.; Centeno, N.B.; et al. Iodine Atoms: A New Molecular Feature for the Design of Potent Transthyretin Fibrillogenesis Inhibitors. PLoS ONE 2009, 4, e4124. [CrossRef]

29. Ghosh, M.; Meerts, I.A.; Cook, A.; Bergman, A.; Brouwer, A.; Johnson, L.N. Structure of human transthyretin complexed with bromophenols: A new mode of binding. Acta Crystallogr. Sect. D Biol. Crystallogr. 2000, 56, 1085-1095. [CrossRef]

30. Iakovleva, I.; Begum, A.; Brännström, K.; Wijsekera, A.; Nilsson, L.; Zhang, J.; Andersson, P.L.; Sauer-Eriksson, A.E.; Olofsson, A. Tetrabromobisphenol A Is an Efficient Stabilizer of the Transthyretin Tetramer. PLOS ONE 2016, 11, e0153529. [CrossRef]

31. Ciccone, L.; Nencetti, S.; Rossello, A.; Stura, E.A.; Orlandini, E. Synthesis and structural analysis of halogen substituted fibril formation inhibitors of Human Transthyretin (TTR). J. Enzym. Inhib. Med. Chem. 2016, 31, 40-51. [CrossRef] [PubMed]

32. Nilsson, L.; Larsson, A.; Begum, A.; Iakovleva, I.; Carlsson, M.; Brännström, K.; Sauer-Eriksson, A.E.; Olofsson, A. Modifications of the 7-Hydroxyl Group of the Transthyretin Ligand Luteolin Provide Mechanistic Insights into Its Binding Properties and High Plasma Specificity. PLoS ONE 2016, 11, e0153112. [CrossRef] [PubMed]

33. Cotrina, E.Y.; Pinto, M.; Bosch, L.; Vilà, M.; Blasi, D.; Quintana, J.; Centeno, N.B.; Arsequell, G.; Planas, A.; Valencia, G. Modulation of the fibrillogenesis inhibition properties of two transthyretin ligands by halogenation. J. Med. Chem. 2013, 56, 9110-9121. [CrossRef] 
34. Pushpakom, S.; Iorio, F.; Eyers, P.A.; Escott, K.J.; Hopper, S.; Wells, A.; Doig, A.; Guilliams, T.; Latimer, J.; McNamee, C.; et al. Drug repurposing: Progress, challenges and recommendations. Nat. Rev. Drug Discov. 2019, 18, 41-58. [CrossRef] [PubMed]

35. Masseoud, D.; Rott, K.; Liu-Bryan, R.; Agudelo, C. Overview of hyperuricaemia and gout. Curr. Pharm. Des. 2005, 11, 4117-4124. [CrossRef]

36. Strilchuk, L.; Fogacci, F.; Cicero, A.F. Safety and tolerability of available urate-lowering drugs: A critical review. Expert Opin. Drug Saf. 2019, 18, 261-271. [CrossRef]

37. López, L.C.; Varea, O.; Navarro, S.; Carrodeguas, J.A.; Sanchez de Groot, N.; Ventura, S.; Sancho, J. Benzbromarone, Quercetin, and Folic Acid Inhibit Amylin Aggregation. Int. J. Mol. Sci. 2016, 17, 964. [CrossRef]

38. Petrukhin, K. Transthyretin Ligands Capable of Inhibiting Retinol-Dependent RBP4-TTR Interaction for Treatment of Age-Related Macular Degeneration, Stargardt Disease, and Other Retinal Disease Characterized by Excessive Lipofuscin Accumulation. US 20150057320 A1, 26 February 2015.

39. Santos, L.; Rodrigues, D.; Alemi, M.; Silva, S.; Ribeiro, C.; Cardoso, I. Resveratrol administration increases Transthyretin protein levels ameliorating AD features-importance of transthyretin tetrameric stability. Mol. Med. 2016, 22, 597-607. [CrossRef]

40. Doyle, M.L. Characterization of binding interactions by isothermal titration calorimetry. Curr. Opin. Biotechnol. 1997, 8, 31-35. [CrossRef]

41. Miller, M.; Pal, A.; Albusairi, W.; Joo, H.; Pappas, B.; Haque Tuhin, M.T.; Liang, D.; Jampala, R.; Liu, F.; Khan, J.; et al. Enthalpy-Driven Stabilization of Transthyretin by AG10 Mimics a Naturally Occurring Genetic Variant That Protects from Transthyretin Amyloidosis. J. Med. Chem. 2018, 61, 7862-7876. [CrossRef]

42. Bulawa, C.E.; Connelly, S.; Devit, M.; Wang, L.; Weigel, C.; Fleming, J.A.; Packman, J.; Powers, E.T.; Wiseman, R.L.; Foss, T.R.; et al. Tafamidis, a potent and selective transthyretin kinetic stabilizer that inhibits the amyloid cascade. Proc. Natl. Acad. Sci. USA 2012, 109, 9629-9634. [CrossRef] [PubMed]

43. Dolado, I.; Nieto, J.; Saraiva, M.J.M.; Arsequell, G.; Valencia, G.; Planas, A. Kinetic assay for high-throughput screening of in vitro transthyretin amyloid fibrillogenesis inhibitors. J. Comb. Chem. 2005, 7, $246-252$. [CrossRef] [PubMed]

44. Razavi, H.; Palaninathan, S.K.; Powers, E.T.; Wiseman, R.L.; Purkey, H.E.; Mohamedmohaideen, N.N.; Deechongkit, S.; Chiang, K.P.; Dendle, M.T.A.; Sacchettini, J.C.; et al. Benzoxazoles as Transthyretin Amyloid Fibril Inhibitors: Synthesis, Evaluation, and Mechanism of Action. Angew. Chem. 2003, 115, 2864-2867. [CrossRef]

45. Furuya, H.; Saraiva, M.J.; Gawinowicz, M.A.; Alves, I.L.; Costa, P.P.; Sasaki, H.; Goto, I.; Sakaki, Y. Production of recombinant human transthyretin with biological activities toward the understanding of the molecular basis of familial amyloidotic polyneuropathy (FAP). Biochemistry 1991, 30, 2415-2421. [CrossRef] [PubMed]

46. Almeida, M.R.; Damas, A.M.; Lans, M.C.; Brouwer, A.; Saraiva, M.J. Thyroxine binding to transthyretin Met 119. Comparative studies of different heterozygotic carriers and structural analysis. Endocrine 1997, 6, 309-315. [CrossRef]

47. Almeida, M.R.; Alves, I.L.; Terazaki, H.; Ando, Y.; Saraiva, M.J. Comparative Studies of Two Transthyretin Variants with Protective Effects on Familial Amyloidotic Polyneuropathy: TTR R104H and TTR T119M. Biochem. Biophys. Res. Commun. 2000, 270, 1024-1028. [CrossRef]

48. Battye, T.G.; Kontogiannis, L.; Johnson, O.; Powell, H.R.; Leslie, A.G. iMOSFLM: A new graphical interface for diffraction-image processing with MOSFLM. Acta Crystallogr. D Biol. Crystallogr. 2011, 67, 271-281. [CrossRef] [PubMed]

49. Bailey, S. The Ccp4 Suite-Programs for Protein Crystallography. Acta Crystallogr. D Biol Crystallogr. 1994, 50, 760-763.

50. Brunger, A.T. Free R-Value-a Novel Statistical Quantity for Assessing the Accuracy of Crystal-Structures. Nature 1992, 355, 472-475. [CrossRef]

51. McCoy, A.J.; Grosse-Kunstleve, R.W.; Adams, P.D.; Winn, M.D.; Storoni, L.C.; Read, R.J. Phaser crystallographic software. J. Appl. Crystallogr. 2007, 40, 658-674. [CrossRef]

52. Emsley, P.; Lohkamp, B.; Scott, W.G.; Cowtan, K. Features and development of Coot. Acta Crystallogr. D Biol. Crystallogr. 2010, 66, 486-501. [CrossRef] [PubMed] 
53. Adams, P.D.; Afonine, P.V.; Bunkóczi, G.; Chen, V.B.; Davis, I.W.; Echols, N.; Headd, J.J.; Hung, L.W.; Kapral, G.J.; Grosse-Kunstleve, R.W.; et al. PHENIX: A comprehensive Python-based system for macromolecular structure solution. Acta Crystallogr. D Biol. Crystallogr. 2010, 66, 213-221. [CrossRef] [PubMed]

54. Schrödinger, L. The PyMOL Molecular Graphics System Version 1.3r1. 2010. Available online: https: //pymol.org/2/ (accessed on 1 September 2020). 